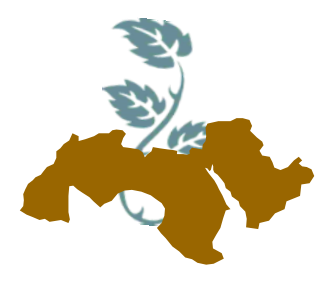

Arab Univ.

J. Agric. Sci., Ain Shams Univ., Cairo, 26(2), 635 - 645, 2018

\title{
MICROPROPAGATION AND START CODON TARGETED CHARACTERIZATION OF FOUR STEVIA CULTIVARS IN EGYPT
}

\author{
Reham, I. Abd ElHamid ${ }^{1 *}$; F.M. Abd ElTawab ${ }^{2}$; A.B. Abdel Razik ${ }^{2}$; \\ A.I. Allam ${ }^{1}$ and A.E.A. ELDoliefy ${ }^{3}$ \\ 1- Tissue culture Dept., Sugar Crops Research Institute, Agric. Research Center (ARC), Giza, \\ Egypt \\ 2- Genetics Dept., Fac. of Agric., Ain Shams Univ., Cairo, Egypt \\ 3- Plant Molecular Biology Dept., Agric. Genetic Engineering Research Institute, Giza, Egypt \\ *Corresponding author: Reham I. Abd El Hamid. email:rehamezz78@gmail.com
}

Keywords: MS medium, Non-caloric sweetener, Stevia rebaudiana, Micropropagation, SCoT marker, CPPU, KIN, BAP

\section{ABSTRACT}

Stevia rebaudiana Bertoni is a natural lowcalorie crop and commercially used as a noncaloric sweetener for diabetic patients. It is also used as cosmetic ingredient, pickling agent, and dentifrice. Four cultivars (Spantia, Shou2A3, China, and High Sugar) of stevia were included to optimize in vitro micropropagation. Four different combinations of hormonal treatments were investigated [6-benzylamino purine (BAP) + Kinetin (Kin) $(0.25+0.25 \mathrm{mg} / \mathrm{l})$; Forchloefenuron $(\mathrm{Cppu})+\mathrm{Kin}$ $(0.25+0.25 \mathrm{mg} / \mathrm{l}) ; \mathrm{Cppu}+\mathrm{Kin}(0.5+0.25 \mathrm{mg} / \mathrm{l})$; and the control medium (hormone-free)]. Out of the different media components, the hormone-free medium produced the best performance of explants. The analysis of variance showed that the control treatment was the most significant for all traits except the number of branches per cutting. Hardening of rooted plants was performed in plastic pots with $70 \%$ survival percentage during acclimatization. Molecular characterization, of the four stevia cultivars, was conducted using 11 SCoT primers. The SCOT analysis resulted in 122 amplicons, of which, 62 amplicons (51\%) were polymorphic. The range of polymorphism was between 6 $\%$ and $91 \%$. The range of polymorphic amplicons per primer was between one and 12 amplicons.
The SCOT-16 produced the highest number of polymorphic bands (12). Meanwhile, the SCoT-24 produced the least polymorphism (6\%). The current study provides a new micropropagation system with low cost, high efficiency, and hormonefree application. Additionally, the study provides the first molecular characterization of stevia using SCoT marker system. Finally, SCoT markers associated with cultivars having high and low contents of stevioside can further be validated by marker-assisted breeding studies.

\section{INTRODUCTION}

Stevia rebaudiana (Bertoni) has long been known to the Indians, as the sweet herb (Madan et al 2010). The herb is natively belong to the Amambay region, in the Northeastern Paraguay, and is found in Argentina and Brazil (Tavarini and Angelini, 2013). The major producing countries of Stevia arelocated in two main regions of China and South Asia. The purified steviol glycoside (Stevioside) was recorded as 300 -times sweeter than the commercially available sucrose (Hwang, 2006). Currently, no large-scale of Stevia farming is common, however, some growth has recorded since the approval of steviol glycoside as one of the food sweeteners (Tavarini and Angelini, 2013). Some drawbacks were found during Stevia propagation. Briefly, seeds of Stevia are small in size and the germination percentage is very low (Singh and Rao, 2005). Given that, the conventional methods 
of using the Stevia cuttings for propagation have produced limited number of plants. Therefore, modern techniques of in vitro propagation, regeneration (tissue culture) and transplantation were required to enhance the production system. Explants (apical bud) produced the highest propagation rate and the efficient root development in Stevia (Anbajhagan et al 2010)

Earlier studies, on tissue culture of Stevia, used the shoot apical meristemwhere culture medium included high levels of kinetin $(10 \mathrm{mg} / \mathrm{l})$ and light intensity (5000 lux). Later, shoot primordial explants and light intensity of 6000 lux were included as modifications (Motomu et al 1994). Stevia rhizogenesis was firstly examined on shoot explants in Murashige and Skoog (MS) medium containing $0.1 \mathrm{mg} / \mathrm{l}$ of 1 -Naphthaleneacetic acid (NAA) as hormonal treatment (Tamura et al 1984). Some reports stated that rhizogenesis in Stevia can be achieved on MS medium including hormone treatments of 6-benzyl amino purine (BAP) and Indole3-butyric acid (IBA) (Ferreria and Handro, 1988). Afterwards, BAP (cytokinin) has become the commonly used hormone for tissue culture in Stevia (Yadav et al 2011a, b). It was also noted that maximum root production could be obtained if MS medium contained $0.5 \mathrm{mg} / \mathrm{l}$ of NAA (Rafiq et al 2007 and Pourvi, 2009).

Traditional methods are considered challenging in Stevia, depending on crosses, physiological and morphological traits to be used for characterization and genetic diversity assessments (Miyagawa et al 1986 and Chalapathi et al 1997). In diploid species of $S$. rebaudiana the pollen was $65 \%$ viable, while in other reports, no viable pollen grains were observed (Oliveira et al 2004 and Monteiro, 1980). Molecular markers, of higher precision and reproducibility, can be the better choice for genetic differentiation, diversity studies and population genetics in Stevia. Genetic diversity in Stevia was previously estimated using RAPD, ISSR, and SSR markers (Hadia et al 2008; Lata et al 2013; Paramanik and Chikkaswamy, 2013; Kaur et al 2015 and Sharma et al 2015). However, to our knowledge, studies using start codon targeted (SCoT) markers were not utilized in Stevia. The SCoT markers system is considered new, as it was designed based on the conserved sequences of start codon (ATG) regions of expressed genes (Collard and Mackill, 2009). SCoT primers were designed to produce dominant markers with ease, low cost, and high polymorphism attributes. The present study is aimed to develop an efficient protocol for in vitro propagation of Stevia and assess the potential of SCoT markers as new molecular application for Stevia characterization.

\section{MATERIALS AND METHODS}

\section{Plant materials and surface sterilization of cut- tings}

Four Stevia cultivars (Spantia, Shou2A3, China and High Sugar) were provided by the Sugar Crops Research Institute (SCRI), Egypt. Five to six centimeters of branched shoots were washed in running tap-water to remove dust, fungal and bacterial spores. In a laminar-flow cabinet, five to six centimeters of branched Stevia shoots were surface-sterilized by immersion in $30 \%$ (v/v) Sodium hypochlorite for $15 \mathrm{~min}$, then rinsed in doubled distilled (dd) $\mathrm{H}_{2} \mathrm{O}$. Nodal segments were further immersed in $0.1 \%(\mathrm{w} / \mathrm{v})$ of Mercury (II) chloride $\left(\mathrm{HgCl}_{2}\right)$ for five minutes. Segments were then rinsed again in dd $\mathrm{H}_{2} \mathrm{O}$. Nodal segments (with a single axillary bud) of about $0.5-0.8 \mathrm{~cm}$ length were prepared aseptically and implanted vertically on MS medium.

\section{Culture condition}

MS culture medium containing $3 \%$ of sucrose was solidified using $0.6 \%$ of agar. The medium $\mathrm{pH}$ was adjusted to 5.9 using $\mathrm{NaOH}(1 \mathrm{~N})$ and/or $\mathrm{HCl}$ $(1 \mathrm{~N})$ solutions, then autoclaved. Culturing medium was designed to include four different combinations of hormonal treatments as follow: 1) BAP + Kin (0.25 + $0.25 \mathrm{mg} / \mathrm{l})$; 2) (Forchloefenuron) Cppu + Kin $(0.25+0.25 \mathrm{mg} / \mathrm{l}) ; 3) \mathrm{Cppu}+\mathrm{Kin}(0.5+0.25$ $\mathrm{mg} / \mathrm{l}$ ); and 4) the control medium (hormone-free). The media were poured in previously autoclaved culture-vessels. The cultures were incubated at $25 \pm 2{ }^{\circ} \mathrm{C}$ and light intensity (2000- 2500 lux) for 16 hours of dark and $60 \%-70 \%$ of relative humidity.

\section{Acclimatization}

Plantlets were washed to eliminate the medium residues adhered to the roots. Then, plantlets were transferred to plastic pots containing soil-mixture [soil: compost $(2: 1 \mathrm{v} / \mathrm{v})$ ] and removed to phytotron under high relative humidity $(60-70 \%)$. After one week, plantlets were transferred to larger pots in the greenhouse. 


\section{Micropropagation and start codon targeted characterization of four Stevia cultivars in Egypt}

\section{Extraction of steviol glycosides and HPLC analysis}

One gram of dried leaves were crushed using pestle and mortar and extraction was performed using combination of methanol and hot water (80 : $20 \mathrm{ml}, \mathrm{v} / \mathrm{v}$ ) for at least 12 hours (overnight) at room temperature. This process was repeated three times, and then the extracted materials were filtered through Whatman paper (Sigma-Aldrich, USA) and completely dried in Rota-vapor (BUCHI, vacuum controller V-850, Switzerland) at $60{ }^{\circ} \mathrm{C}$. The dried samples were then dissolved in $2 \mathrm{ml}$ of methanol absolute. The analysis of high performance liquid chromatography (HPLC) was performed using the Waters modular device (Waters, Milford, USA). The peaks were identified based on the position of co-migrated standard-controls of Rebaudioside A, Stevioside, and Steviol compounds (Sigma-Aldrich, USA).

\section{DNA isolation}

DNA was extracted from the leaves of the four cultivars using the DNeasy Plant Mini Kit (Qiagen Santa Clarita, CA), following the manufacturer's instructions. The DNA quality was assessed based on agarose gel electrophoresis and concentration was confirmed by measuring values of DNA using the Nano-Drop device (TECAN, Infinite M200, Pro Nano Quant).

\section{SCoT primers and PCR reaction}

Twenty SCoT primers were screened and used according to the procedure described by Collard and Mackill (2009). Eleven SCoT primers (Table 4) were selected based on the number of produced amplicons. The PCR reactions were amplified in a total volume of $25 \mu \mathrm{l}$, containing $1 \mathrm{X}$ reaction buffer [Tris- $\mathrm{HCl}(10 \mathrm{mM}), \mathrm{pH} 8.3$ and $\mathrm{KCl}(50 \mathrm{mM})$ ], $\mathrm{MgCl}_{2}$ (1.5 mM), Taq-DNA polymerase (1U) (Promega, US), dNTPs (2.5 mM), primers (25 pmol), and genomic Stevia DNA (30 ng). The PCR was programmed to an initial denaturation cycle at $94^{\circ} \mathrm{C}$ for five minutes, followed by 40 cycles of $94^{\circ} \mathrm{C}$ for 50 seconds, $50{ }^{\circ} \mathrm{C}$ for one minute and $72^{\circ} \mathrm{C}$ for one minute, then final extension cycle at $72^{\circ} \mathrm{C}$ for seven minutes, then the reactions were held at $4^{\circ} \mathrm{C}$. PCR products were then separated on $1.5 \%$ of agarose gel electrophoresis and visualized using UV transilluminator (BioRad, USA).

\section{RESULTS AND DISCUSSION}

\section{Effect of different growth regulators on the cut- tings of Stevia}

The influence of the different growth-regulator treatments, on the five examined traits, of the four cultivars was presented in Table (1) and Fig. (1). Regarding sugar concentration in the medium, other reports showed that single-node explants cultured on MS medium with $1 \%$ sucrose and $0.7 \%$ agar had produced higher number (5.4) of nodes per shoot and higher length of shoots $(4.76 \mathrm{~cm})$ after four-weeks of sub-culturing (Arpan et al 2016). Our data showed that culturing nodel segment explants on MS medium containing $3 \%$ of sucrose and $0.6 \%$ of agar produced higher root length $(9.17 \mathrm{~cm})$ and higher length of shoot (16.69 $\mathrm{cm}$ ) (Table 1). Among the different treatments, the control was the superior, where significant and high length of shoot was scored. These results agreed with (Yücesan et al 2016) who found that effect of MS medium (with or without plant growth regulators) on shoot organogenesis from nodal explants was no significant differences among the treatments concerning the mean number of shoots. Also, it was agreed with another study reported that hormone-free liquid medium was the most suitable out of all other different media tested for in vitro shoot multiplication (Arpan et al 2016). Though the treatment of BAP + Kin (0.25 - 0.25 $\mathrm{mg} / \mathrm{l})$, in our study, exhibited the least mean values in all traits and high number of branching per cutting for all cultivars, with no rooting was observed (Table 1). Three traits differed significantly between the four cultivars, indicating that the treatments were the sources of variation (Table 2). The interaction between cultivars and treatments was significant regarding the root length. Similarly, nodal explants showed insignificant differences in a study for shoot organogenesis under comparable growth regulator treatments in MS media. However, previous reports stated that the maximum number of shoots $(7.82 \pm 0.7)$ was observed when MS medium was supplemented with $0.5 \mathrm{mg} / \mathrm{l}$ of BAP and $0.25 \mathrm{mg} / \mathrm{l}$ of Kinetin at the same period of fourweeks after sub-culture (Razak et al 2014). Also, the highest number of shoots was achieved on MS medium supplemented with $0.6 \mathrm{mg} / \mathrm{l}$ of BAP (Tadhani et al 2006). This means that our results can save the cost of using hormones and produce higher number of plants. 
Table 1. The mean values of five traits scored for four treatments in the four Stevia cultivars.

\begin{tabular}{|c|c|c|c|c|c|c|c|c|}
\hline Cultivars & \multicolumn{4}{|c|}{ Length of shoot } & \multicolumn{4}{|c|}{ Number of leaves } \\
\hline & \multicolumn{8}{|c|}{ Treatments } \\
\hline & $\mathbf{F}$ & T1 & T2 & T3 & $\mathbf{F}$ & T1 & T2 & T3 \\
\hline C1 & $13.37^{\star \star}$ & 08.31 & 07.85 & 04.02 & 11.00 & 07.85 & 11.48 & 07.96 \\
\hline $\mathrm{C2}$ & $16.69^{*}$ & 16.00 & 14.24 & 06.52 & 08.93 & 07.15 & 07.15 & 06.04 \\
\hline C3 & $13.50^{*}$ & 10.93 & 10.54 & 04.13 & 07.04 & 05.78 & 05.26 & 07.81 \\
\hline \multirow{5}{*}{$\begin{array}{c}\text { C4 } \\
\text { LSD }\end{array}$} & $14.00^{*}$ & 11.17 & 09.72 & 06.00 & 21.33 & 20.78 & 24.11 & 20.78 \\
\hline & 03.44 & & & & 03.88 & & & \\
\hline & \multicolumn{4}{|c|}{ Number of branches } & \multicolumn{4}{|c|}{ Number of roots } \\
\hline & \multicolumn{8}{|c|}{ Treatments } \\
\hline & $\mathbf{F}$ & T1 & T2 & T3 & $\mathbf{F}$ & T1 & T2 & T3 \\
\hline C1 & 02.33 & 02.30 & 03.63 & $06.11^{*}$ & $11.19^{\star *}$ & 03.41 & 01.89 & 00.67 \\
\hline $\mathrm{C2}$ & 02.63 & 01.96 & 02.3 & 02.61 & $11.52^{* *}$ & 06.26 & 01.70 & 00.28 \\
\hline C3 & 01.22 & 01.15 & 01.37 & 02.04 & $11.67^{* *}$ & 06.67 & 00.26 & 00.89 \\
\hline C4 & 02.00 & 03.56 & 04.00 & 03.56 & $11.44^{\text {** }}$ & 06.67 & 01.44 & 00.89 \\
\hline \multirow[t]{4}{*}{ LSD } & 02.44 & & & & 04.22 & & & \\
\hline & \multicolumn{4}{|c|}{ Length of root } & & & & \\
\hline & \multicolumn{4}{|c|}{ Treatments } & & & & \\
\hline & $\mathbf{F}$ & $\mathrm{T} 1$ & T2 & T3 & & & & \\
\hline C1 & $06.37^{\star \star}$ & 02.15 & 04.46 & 00.46 & & & & \\
\hline $\mathrm{C} 2$ & $06.17^{*}$ & 03.53 & 0.96 & 00.22 & & & & \\
\hline C3 & $04.43^{*}$ & 02.19 & 00.00 & 00.67 & & & & \\
\hline $\begin{array}{c}\text { C4 } \\
L S D\end{array}$ & $\begin{array}{c}09.17^{\star *} \\
03.90\end{array}$ & 03.67 & 01.13 & 00.39 & & & & \\
\hline
\end{tabular}

Cultivar; C1, Spantia; C2, Shou2A3; C3, China; C4, High sugar. Treatments, F, control; T1, Cppu, Kin (0.25-0.25 $\mathrm{mg} / \mathrm{l})$; T2, Cppu, Kin (0.5-0.25 mg/l); T3, BAP, Kin (0.25-0.25 mg/l). LSD, Least significant difference at $p \leq 0.05 .{ }^{*}$, significance level at $p \leq 0.05$ if mean value is higher than $L S D$ value based on thet-test of difference between twomean values.

Table 2. The analysis of variance of the five traits assessed in the four Stevia cultivars

\begin{tabular}{|c|c|c|c|c|c|c|c|c|}
\hline Trait & \multicolumn{4}{|c|}{ Length of shoot } & \multicolumn{4}{|c|}{ Number of leaves } \\
\hline & $d f$ & MS & F-value & $\boldsymbol{P}$ & $d f$ & MS & $F$-value & $\boldsymbol{P}$ \\
\hline C & 3 & 57.02 & $05.42^{* *}$ & 00.004 & 03 & 605.47 & $52.56^{\star * *}$ & $1.8 \mathrm{E}-12$ \\
\hline $\mathbf{T}$ & 3 & 180.81 & $17.18^{\star \star \star}$ & 07.92E-07 & 03 & 09.369 & 00.81 & 00.49 \\
\hline $\mathrm{C} \times \mathrm{T}$ & 9 & 04.64 & 00.44 & 00.90 & 09 & 05.95 & 00.52 & 00.85 \\
\hline \multirow[t]{3}{*}{ Error } & 32 & 10.52 & & & 32 & 11.52 & & \\
\hline & \multicolumn{4}{|c|}{ Number of branches } & \multicolumn{4}{|c|}{ Number of roots } \\
\hline & $d f$ & MS & $F$-value & $\boldsymbol{P}$ & $d f$ & MS & $F$-value & $P$ \\
\hline C & 03 & 11.24 & 02.74 & 00.06 & 03 & 01.54 & 00.22 & 00.88 \\
\hline $\mathbf{T}$ & 03 & 05.69 & 01.39 & 00.27 & 03 & 296.9 & $42.54^{* * *}$ & $02.8 \mathrm{E}-11$ \\
\hline $\mathrm{C} \times \mathrm{T}$ & 09 & 02.34 & 00.57 & 00.81 & 09 & 02.62 & 00.38 & 00.94 \\
\hline \multirow[t]{3}{*}{ Error } & 32 & 04.11 & & & 32 & 06.98 & & \\
\hline & \multicolumn{4}{|c|}{ Length of root } & & & & \\
\hline & $d f$ & MS & $F$-value & $\boldsymbol{P}$ & & & & \\
\hline C & 03 & 07.52 & $03.30^{*}$ & 00.03 & & & & \\
\hline $\mathbf{T}$ & 03 & 83.48 & $36.67^{\star \star *}$ & $01.81 \mathrm{E}-10$ & & & & \\
\hline $\mathrm{C} \times \mathrm{T}$ & 09 & 05.84 & $02.56^{*}$ & 00.02 & & & & \\
\hline Error & 32 & 02.28 & & & & & & \\
\hline
\end{tabular}

$\mathrm{C}$, source of variance due to cultivar factor; $T$, source of variance due to treatment factor; $\mathrm{C} \times \mathrm{T}$, source of variance due to cultivar by treatment interaction; Error, source of variance due to experimental error. MS, means squares; $d f$, degrees of freedom at $\alpha=0.05,0.01,0.001 ; F$-value, the calculated $F$-value; $P$, probability of significance at $\alpha=0.05$ of type I error. 
Micropropagation and start codon targeted characterization of four Stevia cultivars in Egypt
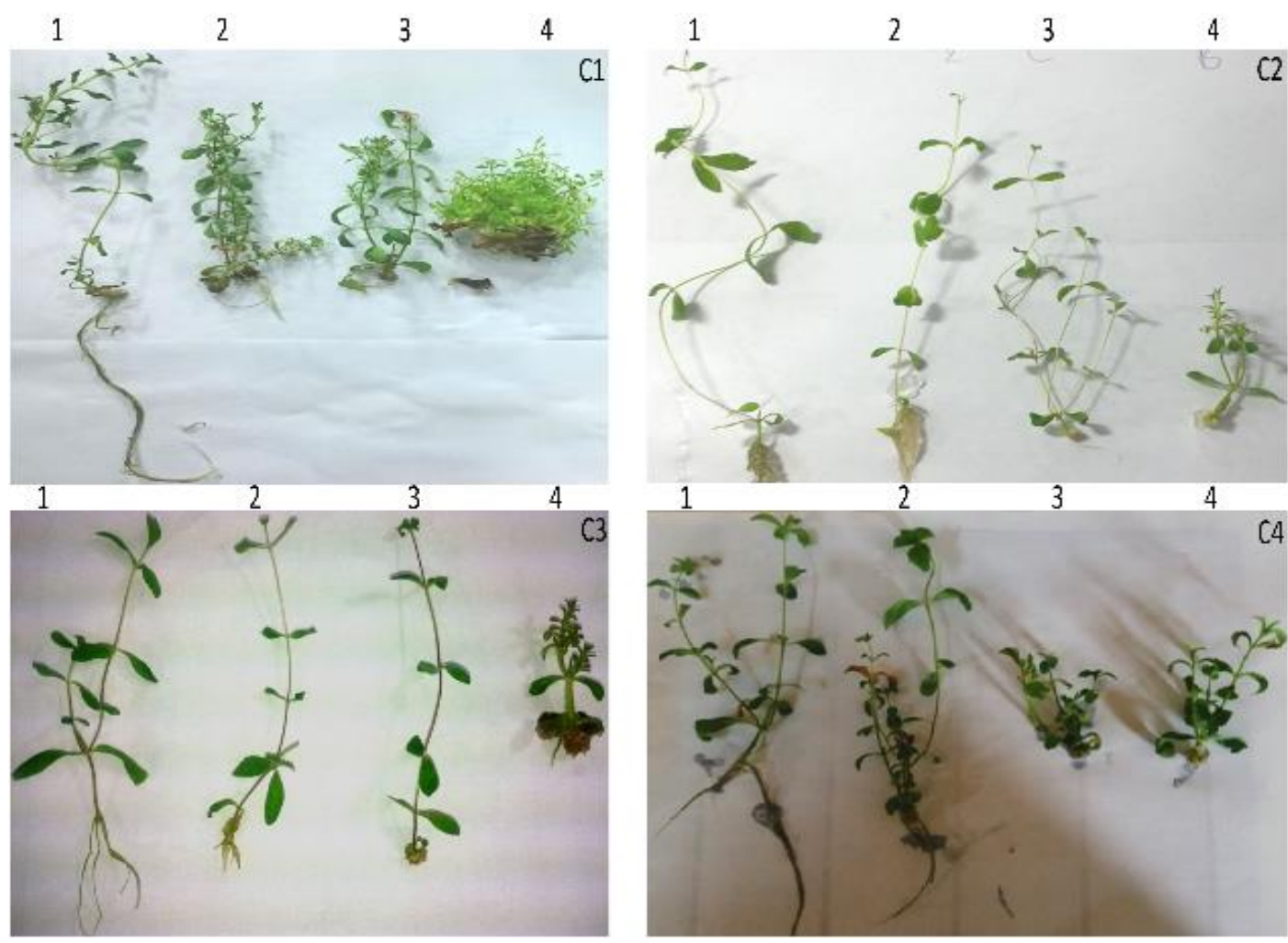

Fig. 1. Explants were influenced by different levels of growth regulator in the four Stevia cultivars. C1, Spantia cultivars; C2, Shou2A3 cultivars; C3, China cultivars; C4, High Sugar cultivars. $1=$ Control treatment; 2, Treatment of Cppu $(0.25 \mathrm{mg} / \mathrm{l})+$ Kin $(0.25 \mathrm{mg} / \mathrm{l}) ; 3$, Treatment of Cppu $(0.5 \mathrm{mg} / \mathrm{l})+\mathrm{Kin}(0.25$ $\mathrm{mg} / \mathrm{l}) ; 4$, Treatment of BAP $(0.25 \mathrm{mg} / \mathrm{l})+\mathrm{Kin}(0.25 \mathrm{mg} / \mathrm{l})$.

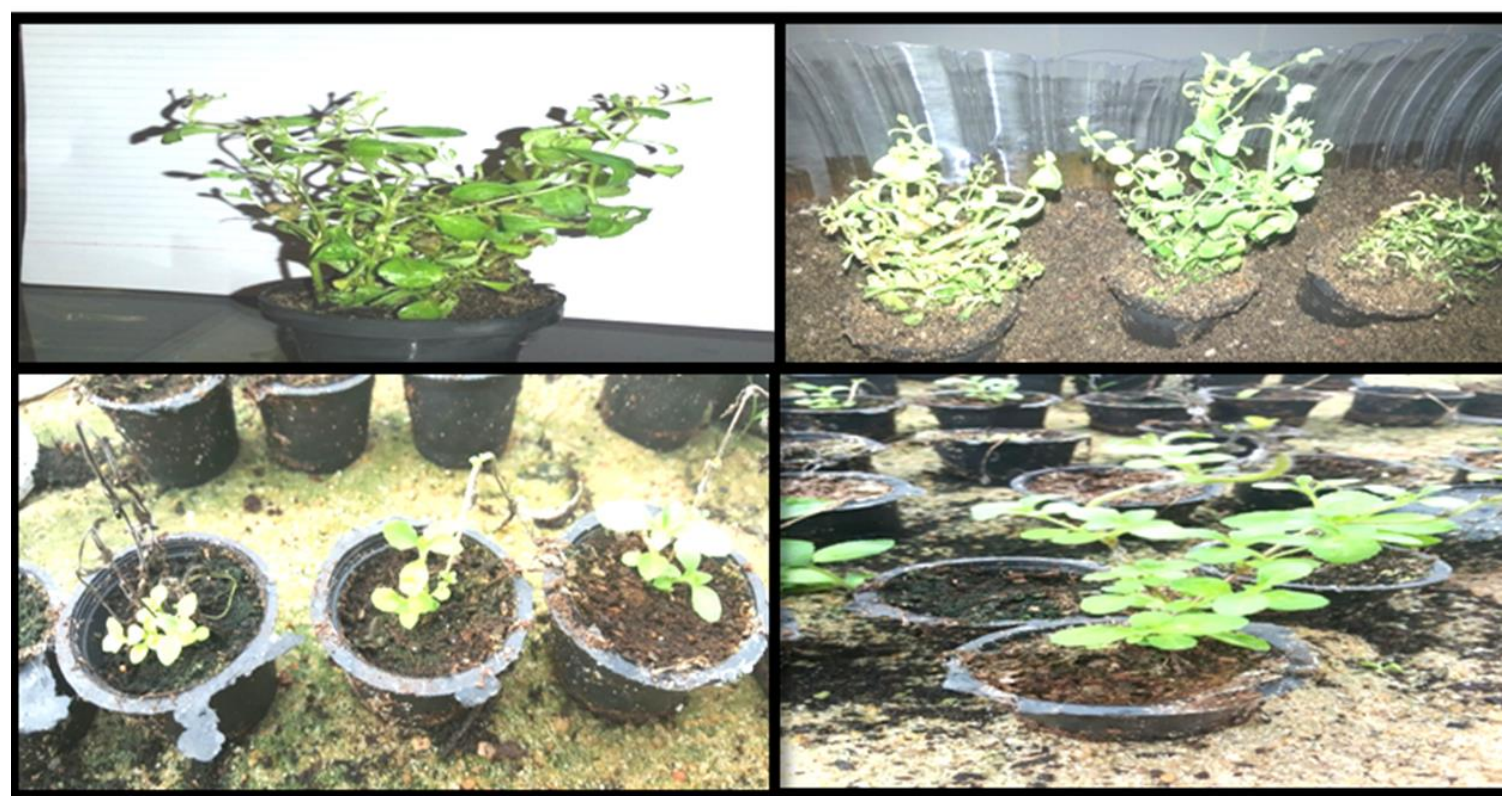

Fig. 2. Acclimatization of Stevia transplants in plastic pots 


\section{Acclimatization}

Nodal-segment explants were transferred to small plastic pots [soil: compost $(2: 1 \mathrm{v} / \mathrm{v})$ ] that was previously treated with fungicide $(0.1 \%$ of agrosan). Almost $70 \%$ of survival rate was obtained during acclimatization. Plantlets were then covered with transparent polyethylene bags and placed in the growth room $\left(28 \pm 2^{\circ} \mathrm{C}, 70-90 \%\right.$ relative humidity, and light intensity (1500 lux) for three weeks. Afterword, polyethylene bags were opened. Plantlets were then placed in ambient room temperature for two weeks, then transferred and shade-covered in the field for four weeks to avoid direct sunlight (Fig. 2). This result was in agreement with attributed foundations for quicker and better sprouting, under greenhouse conditions, that were emphasized due to higher temperature $\left(30^{\circ} \mathrm{C}\right)$ and relative humidity (85\%) in comparison to natural shaded conditions (Umesha et al 2011). Another report suggested that higher biomass production in vermicompost media may be due to increased nutrient uptake and enhanced availability of nutrients and growth promoting (six growth regulators) (Thankamani et al 2005).

\section{Extraction of Steviol glycosides and HPLC analysis}

Though improved influence of CPPU was previously reported for fruit size, and cluster weight in grapes and kiwi, the proportion of stevioside and rebaudioside were not increased in any of the four cultivars that were treated with Cppu $0.25 \mathrm{mg} / \mathrm{l}$. However, only the High Sugar cultivar showed changed values for stevioside and rebaudioside from 634.32 and 281.57 to 816.55 and 636.13 $\mathrm{mg} / 100 \mathrm{~g}$, respectively. High Sugar and China cultivars were consistent at the morphological and chemical trait assessments (Table, $\mathbf{3}$ ).

Table 3. Stevioside and rebaudioside contents in the leaves of the four Stevia cultivars using HPLC

\begin{tabular}{|c|c|c|}
\hline \multirow{2}{*}{$\begin{array}{l}\text { Chemical } \\
(\mathrm{mg} / 100 \mathrm{~g})\end{array}$} & \multicolumn{2}{|r|}{ Treatments } \\
\hline & Control & $\begin{array}{c}\text { CPPU }(0.25 \mathrm{mg} / \mathrm{l})+ \\
\operatorname{Kin}(0.25 \mathrm{mg} / \mathrm{l})\end{array}$ \\
\hline & \multicolumn{2}{|r|}{ C1 } \\
\hline Stevioside & 322.49 & 284.81 \\
\hline \multirow[t]{2}{*}{ Rebaudioside } & 173.48 & 173.18 \\
\hline & \multicolumn{2}{|r|}{ C2 } \\
\hline Stevioside & 457.71 & 411.35 \\
\hline \multirow[t]{2}{*}{ Rebaudioside } & 301.14 & 256.57 \\
\hline & \multicolumn{2}{|r|}{ C3 } \\
\hline Stevioside & 699.80 & 642.82 \\
\hline \multirow[t]{2}{*}{ Rebaudioside } & 767.88 & 625.78 \\
\hline & \multicolumn{2}{|r|}{ C4 } \\
\hline Stevioside & 634.32 & 816.55 \\
\hline Rebaudioside & 281.57 & 636.13 \\
\hline
\end{tabular}

C1, cultivar Spantia; C2, cultivar Shou2A3; C3, cultivar China; C4, cultivar High sugar. CPPU, Forchloefenuron; KIN, Kinetin.

Table 4. SCOT primer names, sequences, and polymorphism

\begin{tabular}{|c|c|c|c|c|}
\hline Primer name & Primer sequence (5'-3') & NTB & NPB & PIC\% \\
\hline SCoT- 6 & CAATGGCTACCACTACAG & 5 & 2 & 0.4 \\
SCoT- 9 & ACAATGGCTACCACTGCC & 8 & 2 & 0.25 \\
SCoT-10 & ACAATGGCTACCACCAGC & 11 & 10 & 0.91 \\
SCoT-16 & CCATGGCTACCACCGGCA & 17 & 12 & 0.71 \\
SCoT-24 & CCATGGCTACCACCGCAG & 16 & 1 & 0.06 \\
SCOT-28 & CAACAATGGCTACCACCA & 8 & 1 & 0.125 \\
SCoT-32 & CAACAATGGCTACCACGC & 14 & 11 & 0.13 \\
SCoT-35 & AACCATGGCTACCACCAC & 11 & 10 & 0.79 \\
SCoT-36 & CACCATGGCTACCACCAT & 16 & 7 & 0.44 \\
SCoT-44 & ACCATGGCTACCACCGAC & 8 & 4 & 0.5 \\
SCoT-46 & ACCATGGCTACCACCGCC & 8 & 2 & 0.25 \\
\hline
\end{tabular}

NTB, number of total amplified bands; NPB, number of polymorphic bands; PIC, percentage of information contents 

Stevia cultivars in Egypt

Table 5. Number of amplified fragments of SCoT markers in the four cultivars of Stevia

\begin{tabular}{|c|c|c|c|c|c|c|c|c|c|c|c|c|}
\hline & \multicolumn{12}{|c|}{ SCoT Primers } \\
\hline & 6 & 9 & 10 & 16 & 24 & 28 & 32 & 35 & 36 & 44 & 46 & Total \\
\hline & \multicolumn{12}{|c|}{ C1 } \\
\hline AF & 4 & 8 & 5 & 12 & 16 & 7 & 5 & 4 & 14 & 5 & 7 & 87 \\
\hline \multirow[t]{2}{*}{ SM } & 1 & 0 & 2 & 3 & 0 & 0 & 3 & 1 & 1 & 0 & 1 & 12 \\
\hline & \multicolumn{12}{|c|}{$\mathrm{C} 2$} \\
\hline AF & 3 & 8 & 9 & 12 & 15 & 8 & 12 & 3 & 10 & 5 & 7 & 92 \\
\hline \multirow[t]{2}{*}{ SM } & 0 & 0 & 1 & 3 & 0 & 0 & 4 & 2 & 2 & 1 & 0 & 13 \\
\hline & \multicolumn{12}{|c|}{$\mathrm{C} 3$} \\
\hline AF & 3 & 8 & 9 & 13 & 16 & 8 & 7 & 9 & 13 & 7 & 7 & 100 \\
\hline \multirow[t]{2}{*}{ SM } & 0 & 0 & 0 & 0 & 0 & 0 & 0 & 2 & 1 & 1 & 0 & 4 \\
\hline & \multicolumn{12}{|c|}{ C4 } \\
\hline AF & 4 & 6 & 2 & 10 & 15 & 7 & 9 & 7 & 13 & 7 & 8 & 88 \\
\hline SM & 1 & 1 & 2 & 1 & 0 & 0 & 2 & 0 & 0 & 0 & 0 & 7 \\
\hline TSM & 2 & 1 & 5 & 7 & 0 & 0 & 9 & 5 & 4 & 2 & 1 & 36 \\
\hline PB & 2 & 2 & 10 & 12 & 1 & 1 & 11 & 10 & 7 & 4 & 2 & 62 \\
\hline TAF & 14 & 30 & 25 & 47 & 62 & 30 & 33 & 23 & 50 & 24 & 29 & 364 \\
\hline
\end{tabular}

Comp, comparison of parameters within each cultivar (C1, Spantia; C2, Shou2A3; C3, China; and C4, High sugar); AF, amplified fragments; SM, number of single markers; TSM, total single markers; PB, polymorphic bands; TAF, total amplified fragments
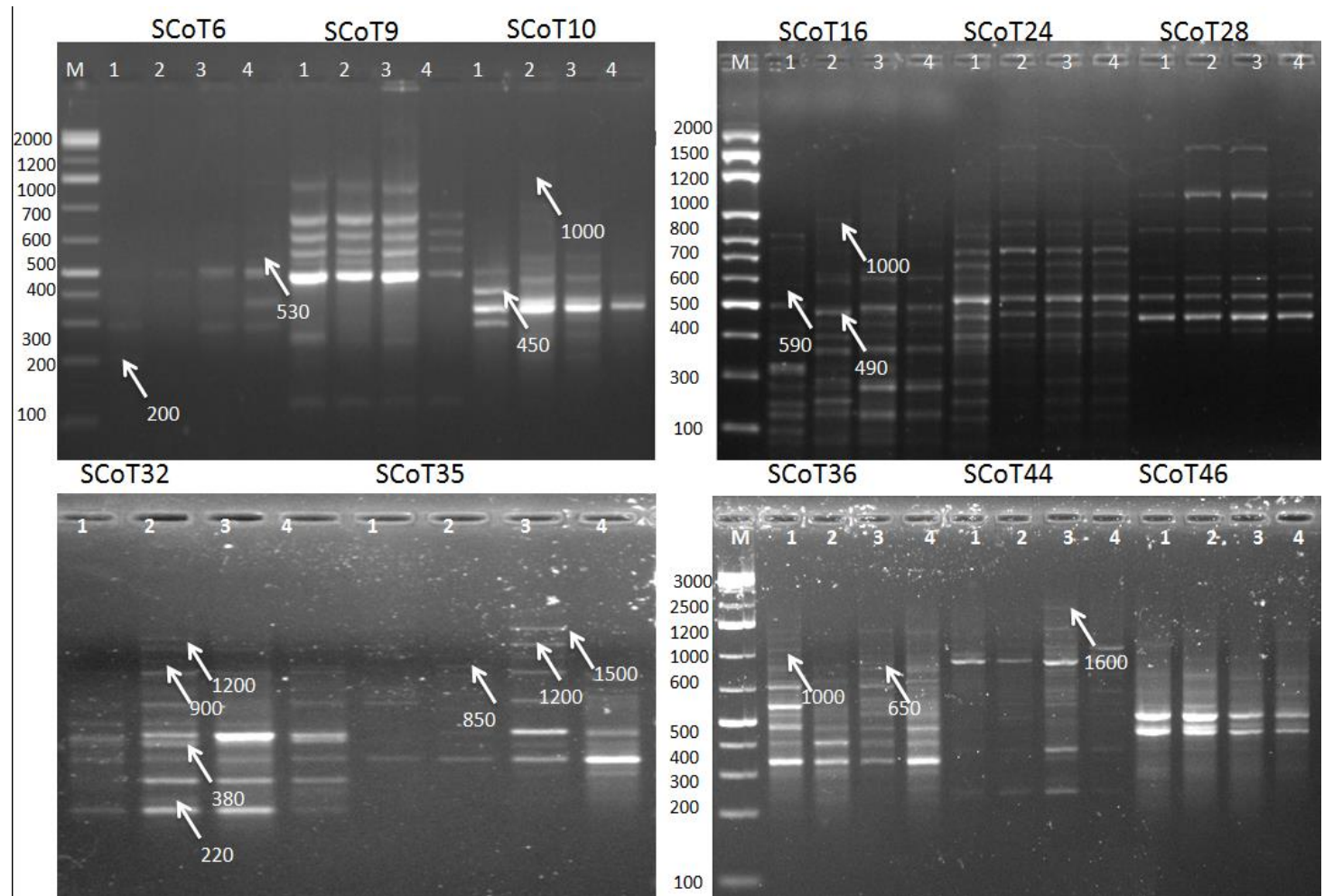

Fig. 3. The patterns of the eleven SCoT markers of the four Stevia cultivars. The lanes coded as M represented the 100bp DNA Ladder (VivantisTechnology), the lanes coded as 1 represented the Spantia cultivars, the lanes coded as 2 represented the Shou2A3 cultivar, the lanes coded as 3 represented the China cultivar, the lanes coded as 4represented the High Sugar cultivar. The (white arrows)indicated the unique amplicons of the characterized cultivars. 


\section{Molecular characterization using SCoT markers}

Until recently, molecular marker studies in Stevia were based on ISSR and RAPD (Hadia et al 2008; Lata et al 2013; Paramanik \& Chikkaswamy, 2014; Kaur et al 2015 and Sharma et al 2015). To our knowledge, the present study can be considered the first to use SCoT markers in Stevia. Unlike RAPD and ISSR markers, SCoT markers are designed based on its physical existence within the functional genes. Thus, SCOT amplicons can be converted into gene-hunting marker systems (Xiong et al 2011). Besides, SCOT markers are multiloci-dependent and can be used to produce characteristic polymorphism among cultivars. In our study, 11 SCOT primers were used to amplify 122 total amplicons (Table 4). Among which, 62 amplicons were polymorphic and represented $51 \%$ of total polymorphism (Table 5). The percentage of polymorphism was ranged from six to $91 \%$. The range of the number of polymorphic amplicons per primer was between one and 12 fragments. The primer of SCoT-16 produced the highest number of polymorphic bands (12). One primer (SCoT-24) showed the least percentage of polymorphism $(6 \%)$. Most importantly, the unique and single markers can be used to differentiate and characterize between the four cultivars (Fig. 3). In SCoT6 , two fragment-sized amplicons at $530 \mathrm{bp}$ and 200 bp were differentially produced and characterized the cultivars High Sugar and Spantia, respectively. In the current study, the cultivars High Sugar and Spantia showed the higher and the lower levels of Stevioside (634.32 and $322.49 \mathrm{mg} / 100 \mathrm{~g}$; respectively) (Table 3 ). Thus, the two fragmentsized amplicons of SCoT- 6 can further be used in association studies to assess its correlation with high and low levels of Stevioside in Stevia. In SCoT-10, a fragment-sized amplicon at $1000 \mathrm{bp}$ was produced and identified the cultivar Shou2A3 out of the other three Stevia cultivars. Based on the HPLC analysis, the Shou2A3 cultivar showed a middle-low level of Stevioside (457.71 mg/100 g). Additionally, the Shou2A3 cultivar can be identified by another two fragment-sized amplicons at 490 bp and 1000 bp of SCoT-16. In SCoT-32, a fragment-sized amplicon at $260 \mathrm{bp}$ had differentially identified the cultivar China. In this study, the China cultivar showed a high level of Stevioside $(634.32 \mathrm{mg} / 100 \mathrm{~g})$; based on the HPLC results.

\section{CONCLUSION}

Out of the different media compositions included in current study for in vitro multiplication, hormone-free medium was the most efficient. High sugar and China cultivars have shown consistent results at the morphological and chemical traits assessment. The cultivar Spantia was comparatively characterized for low level of Stevioside (322.49 $\mathrm{mg} / 100 \mathrm{~g}$ ) using the HPLC analysis and can be identified by using the SCoT-6 (200 bp), SCoT-10 (450 bp), SCoT-16 (590 bp), and SCoT36 (1000 bp). The cultivar Shou2A3 was comparatively characterized for middle-low levels of Stevioside $(457.71 \mathrm{mg} / 100 \mathrm{~g})$ using HPLC data and can be identified by using the SCoT-10 (1000 bp), SCoT-16 (1000 bp), SCoT-32 (220, 380, 900, and 1200 bp), SCoT-35 (850 bp), and SCoT-36 (220 bp). The cultivar High Sugar was comparatively characterized for middle-high level of Stevioside $(634.32 \mathrm{mg} / 100 \mathrm{~g})$ using the HPLC analysis and can be identified by using the SCoT-6 (530 bp). The cultivar China was comparatively characterized for the highest level of Stevioside (699.80 $\mathrm{mg} / 100 \mathrm{~g}$ ) using the HPLC analysis and can be identified by using the SCoT-32 (260 bp), SCoT-36 (650 bp), and SCoT-44 (1600 bp). For the first time, this study has successfully validated the SCoT marker as a new molecular tool to differentiate between Stevia cultivars. Moreover, cultivarspecific markers can further be applied for genotyping and association studies of quality traits that require stevioside and rebaudioside-A in Stevia.

\section{REFERENCES}

Anbajhagan, M., Kalpana, M., Rajendran, R., Natarajan, V. and Dhanavel, D., 2010. In vitro production of Stevia rebaudiana Bert.. Emir. J. Food Agric., 22, 216-222.

Arpan, R.. Vikas, S., Ghanshyam, P., Amritpal, S., Subhash, N. and Nitish K., 2016. Micropropagation and Biomass Production of Trueto-Type Stevia rebaudiana Bertoni S. Mohan Jain (ed.), Protocols for In Vitro Cultures and Secondary Metabolite Analysis of Aromatic and Medicinal Plants, Second Edition, Methods in Molecular Biology, pp. 1391-1395.

Collard, B.C.Y. and David J.M. 2009. Start Codon Targeted (SCOT) Polymorphism: A Simple, Novel DNA Marker Technique for Generating Gene-Targeted Markers in Plants. Plant Mol. Biol. Rep., 27, 86-93. 
Ferreria, C.M. and Handro, W. 1988. Production, maintenance and plant regeneration from cell Suspension Culture of Stevia rebaudiana (Bert.) Bertoni. Plant Cell Report, 7, 123-126.

Hadia, H.A., Badawy, O.M. and Afaf M.H. 2008. Genetic Relationships among Some Stevia (Stevia Rebaudiana Bertoni) Accessions Based on ISSR Analysis. Res. J. Cell Mol. Bio., 2(1), 1-5.

Hwang, S.J. 2006. Rapid in vitro propagation and enhanced stevioside accumulation in Stevia rebaudiana Bert.. J. Plant Biol. ,49, 267-270.

Kaur, R., Sharma, N. and Ravinder, R. 2015. Identification and functional annotation of expressed sequence tags based SSR markers of Stevia rebaudiana. Turk. J. Agric., 39, 1-12.

Lata, H., Chandra, S., Techen, N., Wang, Y.H. and Ikhlas, A.K. 2013. Molecular Analysis of Genetic Fidelity in Micropropagated Plants of Stevia rebaudiana Bert. Using ISSR Marker. Amer J. Plant Sci., 4, 964-971.

Madan, S., Ahmad, S., Singh, G.N., Kohli, K., Kumar, Y., Singh, R. and Garg, M. 2010. Stevia rebaudiana (Bert.) Bertoni - a review. Indian J. Nat. Prod., 1, 267-286.

Miyagawa, H., Fujikowa, N., Kohda, H., Yamasaki, K., Taniguchi, K. and Tanaka R. 1986. Studies on the tissue culture of Stevia rebaudiana and its components: (II). Induction of shoot primordia. Planta Med., 4, 321-324.

Monteiro, R. 1980. Taxonomia e biologia da reproducao da Stevia rebaudiana Bert Ph.D. thesis Univ. Estadual de Campinas Brazil [English abstract.]

Motomu, A., Shigeoka, T., Koizumi, Y. and Kawamura, M. 1994. Mass propagation of shoots of Stevia rebaudiana using a large scale bioreactor. Plant Cell Reports, 13(3-4), 180-183.

Oliveira, V.M., Forni-Martins, E.R., Magalhaes, P.M. and Alves, M.N. 2004. Chromosomal and morphological studies of diploid and polyploid cytotypes of Stevia rebaudiana (Bertoni) (Eupatorieae, Asteraceae) Genet. Mol. Biol., 27, 215-222.

Paramanik, R.C. and Chikkaswamy, B.K. 2014. Study on Genetic Diversity relationship some Medicinal plantsusing RAPD Molecular marker. Int. J. Curr. Micro Bio. App. Sci., 3(6), 10041015.
Pourvi, J., Kachhwaha, S. and Kothari, S.L. 2009. Improved micropropagation protocol and enhancement in biomass and chlorophyll content in Stevia rebaudiana (Bert.) Bertoni by using high copper levels in the culture medium. Scientia Horticulturae, 119(3), 315-319.

Rafiq, M., Muhammad, U.D., Sher, M.M., Naqvi, H.A. and Qarshi, I.A. 2007. In Vitro Clonal Propagation and Biochemical Analysis at Field Established Stevia rebaudiana Bertoni. Pakistanian J. of Botany, 39(7), 2467-2474.

Razak , U.N.A.A., Ong, C.B., Yu, T.S. and Lau, L.K. 2014. In vitro Micropropagation of Stevia rebaudiana Bertoni in Malaysia. Brazilian Archives of Biology and Technology., 57(1), 23-28.

Sharma, N., Kaur, R. and Vaidya, E. 2015. Potential of RAPD and ISSR markers for assessing genetic diversity among Stevia rebaudiana Bertoni accessions. Ind. J. Biotech. 15, 95-100.

Singh, S.D. and Rao, G.P., 2005. Stevia: the herbal sugar of 21 st century. Sugar Tech., 7, 17-24.

Tadhani, M.B., Jadeja, R.P. and Rena, S. 2006. Micropopagation of Stevia rebaudiana Bertoni using multiple shoot culture. J. Cell Tissue Res., 6, 545-548.

Tamura, Y., Nakamura, S., Fukui, H. and Tabata, M. 1984. Clonal propagation of Stevia rebaudianaBertoni by stem-tip culture. Plant Cell Report, 3, 183-185.

Tavarini, S. and Angelini, L.G. 2013. Stevia rebaudiana Bertoni as a source of bioactive compounds: the effect of harvest time, experimental site and crop age on steviol glycoside content and antioxidant properties. J. Sci. Food Agric., 93, 2121-2129.

Thankamani, C.K., Sreekala, K. and Anandaraj, M. 2005. Effect of Pseudomonas fluorescens (IISR-6) and Trichoderma harzianum (P-26) on growth of black pepper (Piper nigrum L.) in the nursery. J. SpicesArom. Crops, 14(2), 112116.

Umesha, K., Murthy, G. and Smitha, G.R. 2011. Environmental conditions and type of cuttings on rooting and growth of vanilla (Vanilla planifolia Andrews). J. Trop. Agric., 49 (1-2), 121123. 
Xiong, F., Zhong, R., Han, Z., Jiang, J., He, L., Zhuang, W. and Tang, R., 2011. Start codon targeted polymorphism for evaluation of functional genetic variation and relationships in cultivated peanut (Arachis hypogaea L.) genotypes. Mol. Biol. Rep., 38, 3487-3494.

Yadav, K. and Singh, N. 2011a. In vitro propagation and biochemical analysis of field established Wood apple (Aegle marmelos L.). Analele Universitãpii din Oradea - Fascicula Biologie, 18(1), 23-28.
Yadav, K. and Singh, N. 2011b. In vitro flowering of shoots regenerated from cultured nodal explants of Spilan the sacmella Murr. - An ornamental cum medicinal herb. Analele Universitãpii din Oradea - Fascicula Biologie, 18(1), 60-64.

Yücesan, B., Mohammed, A., Büyükgöçmen, R., Gürel, E., Altuğ, C., Kavas, Ö. and Gürel, S. 2016. In vitro and ex vitro propagation of Stevia rebaudiana Bertoni with high Rebaudioside-A content-A commercial scale application. Scientia Horticulturae, 203, 20-28. 